\title{
Exclusive breastfeeding up to 6 months
}

\author{
Aulakh R \\ Dr. Roosy Aulakh, Associate Prof, Dept. of Pediatrics, Govt. Medical College \& Hospital, Sector 32, Chandigarh, India.
}

Address for correspondence: Email: drroosy@gmail.com

We read with interest the article on knowledge, attitude and practices of complimentary feeding of infants by Venugopal $\mathrm{S}$ et al.[1]. The mean age of knowledge regarding complementary feeding in this study was 7.99 months which is more than the recommended 6 months. Improper complimentary feeding is often observed in infants presenting with Infantile Tremor Syndrome (ITS). Despite numerous reported case series on Infantile Tremor Syndrome (ITS), the etiological still remains obscure. One uniform finding in all these reports have been the occurrence of this syndrome in children with similar demographic profile- age between 6 and 18 months, predominantly males, belonged to lower socio-economic strata, and exclusively breastfed by predominantly vegetarian mothers.

\section{Reply from editor}

Thanks for the excellent query on complementary feeding. There is lack of awareness of complimentary feeding amongindian mothers. Many are unaware about role of macro \& micronutrients, concept of nutrient density,minimum meal frequency, minimum diet diversity \& minimum acceptable diet,importance of timely introduction \& monitoring of complementary feeding. Many don't understand taste development \& palate programming of infants \& generally ignore food preferences. Many don't know to prepare homemade \& fortified complimentary foods. Regarding early introduction of complementary feeds, in developing country like ours, exclusive breastfeeding is considered the best strategy to prevent early childhood deaths, followed by improving quality of complementary feeding [2]. An infant achieves double the birth weight by 6 months\& exclusive breastfeeding is insufficient to meet increasing nutrient demands [3].Hence its time to think seriously about early complimentary nutrition.

Regarding micro \& macronutrient deficiency, in developing countries, poor nutrient density of food may contribute to reduced availability of nutrients such as iron, zinc, riboflavin, niacin, thiamine, folate, vitamin
An interesting observation over last 6 months in our center has been the detection of ITS in two four month old exclusively breastfed children of strict vegetarian mothers. Vitamin B12 deficiency was detected in both these infant-mother dyads. This observation incited a debate in our minds that whether one should recommend exclusive breastfeeding for six months as a universal principal or actually suggest earlier start (4 months) of complimentary diet (including food from animal sources) to such infants of nutritionally deficient mothers. If children on exclusive breastfeeds by nutritionally deficient mothers manifest symptoms of micronutrient deficiency before 6 months of age, then shouldn't this recommendation of exclusive breastfeeding upto 6 months be critically reviewed ?

B6, vitamin B12, calcium, iodine, selenium, vitamin A, vitamin $\mathrm{C} \&$ vitamin $\mathrm{E}$ [4]. Children are most vulnerable to undernutrition during 6-24 months. Only $22 \%$ of breastfed infants, $12 \%$ of nonbreastfed children \& $21 \%$ of all infants between 6-23 months of age are adequately fed [5]. Adding animal-source foods in older infants, mixing of micronutrient sprinkles or nutrientrich pastes, regular supplementation with micronutrient drops or capsules, centrally processed fortified foods can ensure adequate complementary nutrition. Nutrientdense adequate complementary foods are required to fill the gap between total nutritional needs \& amounts provided by breast milk.

\section{Dr. Rabindran,}

Consultant Neonatologist, Billroth Hospital, Chennai

Address for correspondence: Dr Rabindran, E mail: rabindranindia@yahoo.co.in

\section{References}

1. Venugopal. S, Chandrashekar. Knowledge of complementary feed and its effect on the child nutrition. Pediatr Rev: Int J Pediatr Res 2016; 3(1):2431.doi:10.17511/ijpr.2016.1.05. 
2. Krebs NF. Food based complementary feeding strategies for breastfed infants: What's the evidence that it matters? Nutr Today. 2014;49(6):271-277.

3. World Health Organization. Infant and young child feeding (IYCF) Model Chapter for textbooks for medical students and allied health professionals. 2009.
4. Dewey KG. The challenge of meeting nutrient needs of infants and young children during the period of complementary feeding: An evolutionary perspective. J Nutr. 2013;143:2050-2054.

5. Das J, Salam R, Kumar R, Bhutta Z. Micronutrient fortification of food and its impact on woman and child health: A systematic review. Systematic Reviews. 2013;2(1):67.

\section{How to cite this article?}

Aulakh R. Exclusive breastfeeding up to 6 months. Paed Rev: Int J Pediatr Res 2016;3(4):281282.doi:10.17511/ijpr.2016.i04.14. 